2. Auf angewandte Chemie bezügliche Methoden, operationen, Apparate und Reagenzien.

$$
\text { ron }
$$

\title{
W. Tetzlaff.
}

Über kolorimetrische Kohlenstoffbestimmungen berichtet Ed. Maurer ${ }^{1}$ ) in seiner Abhandlung: Untersuchungen über das Härten and Anlassen von Eisen und Stahl. ${ }^{2}$ ) Der Verfasser macht darauf aufmerksam, dass Differenzen im Kohlenstoffgehalt bei abgeschreckten und wieder angelassenen, beziehungsweise ausgeglühten Stahlproben bei der kolorimetrischen Bestimmung des Kohlenstoffs auftreten. Diese Tatsache wird noch nicht genügend von den Stahlwerksingenieuren beachtet; manche von ihnen schieben die Schuld an solchen Differenzen einer unrichtigen Arbeitsweise in den verschiedenen Laboratorien za, während doch einzig and allein die Ursache hierfür in der verschiedenen thermischen Behandlung des Stahls liegt. Maurer hat folgende Tabelle aufgestellt, in welcher die kolorimetrisch bestimmten Kohlenstoffgehalte eines und desselben Stahls bei verschiedener thermischer Behandlung verzeichnet sind:

\begin{tabular}{|c|c|c|c|c|c|c|c|c|}
\hline \multirow{2}{*}{\multicolumn{6}{|c|}{ Stahl bei 800 bis $900^{\circ} \mathrm{C}$. abgeschreckt }} & \multicolumn{3}{|c|}{ Kohlenstoff } \\
\hline & & & & & & & & 0,67 \\
\hline Der & abgeschreckte & Stahl & bei & $100^{\circ}$ & C. & & & 0,72 \\
\hline « & $\ll$ & « & « & $200^{\circ}$ & $\ll$ & & & 0,80 \\
\hline * & « & $\ll$ & $\ll$ & $300^{\circ}$ & $\ll$ & Ðี & & 0,86 \\
\hline « & « & $\ll$ & $\ll$ & $380^{\circ}$ & $\ll$ & 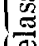 & & 0,93 \\
\hline$\approx$ & « & $\approx$ & $\ll$ & $400^{\circ}$ & $\ll$ & 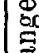 & & 0,93 \\
\hline$\ll$ & $*$ & $\ll$ & $\ll$ & $550^{\circ}$ & * & & & 0,98 \\
\hline « & * & ж & & $750^{\circ}$ & $\ll$ & & & 1,00 \\
\hline
\end{tabular}

Ein neues Kolorimeter zur raschen Bestimmung des Kohlenstoffs in Stahl und Eisen hat Paravicini ${ }^{3}$ ) konstruiert. Dieser Apparat ist im Laboratorium der Hagener Gussstahlwerke im Gebrauch und besitzt versehiedene Vorzüge. Bei ihm ist der Kohlenstoffgehalt direkt abzulesen; es fällt das umständliche Gleichstellen der Töne mit Wasser fort und man kann das Kolorimeter unter Verwendung einer

1) Stahl und Eisen 29. 1234.

2) "Metallurgie" 1909, Seite 33.

3) Stahl und Eisen 29, 1233 , 